\title{
ESTIMULAÇÃO VISUAL PARA RECÉM-NASCIDOS PREMATUROS: Intervenção de enfermagem '
}

\author{
VISUAL STIMULATION FOR PREMATURE NEW-BORNS: A NURSING INTERVENTION \\ ESTIMULACIÖN VISUAL PARA RECIÉN NACIDOS PREMATUROS: INTERUENCIÓN DE \\ ENFERMERÍA
}

\author{
Kelly Monte Sousa ${ }^{2}$ \\ Lorita Marlena Freitag Pagliuca ${ }^{3}$
}

\begin{abstract}
RESUMO: A visão permite assimilar o ambiente, auxiliando na construção do conhecimento. O recém-nascido necessita de tempo para desenvolver alguns órgãos e sentidos, dentre eles a visão. A estimulação visual precoce no prematuro pode prevenir atrasos no seu desenvolvimento psicomotor e social, permitindo avaliar a função visual. Neste estudo, um grupo experimental foi submetido pela enfermagem ao processo de estimulação e avaliação visual e outro, o controle, fol apenas avaliado. A análise dos dados considerou o tempo de exposição, os utensílios utilizados, o número de dias e a resposta à estimulação. Constatou-se que os recém-nascidos submetidos à estimulação visual mostraram-se alertas, ativos e atentos; os do grupo controle encontravam-se desinteressados e pouco ativos frente ao estímulo. Percebeu-se que o programa de estimulação permitirá detectar distúrbios visuais pela avaliação constante das respostas.
\end{abstract}

UNITERMOS: Estimulação visual - Prematuros - Saúde ocular - Intervenção de enfermagem.

ABSTRACT: Vision allows us to assimilate the environment, helping us to construct knowledge. New-borns need time to develop some organs and senses, among them vision. The early premature visual stimulation may prevent its psycho-motor and social development from being late. In this study an experimental group has been submitted to stimulation process and visual evaluation and other group, the control one, was only evaluated. Data analysis considered exposure time, tool used, number of days and stimulation response. It has been verified that new-borns submitted to visual stimulation are alert, active and attentive; those from the control group are uninterested and stimulus little active. It has been noticed that the stimulation programme will permit visual disturbances to be detected b constant response evaluation.

KEYWORDS: Visual stimulation - Prematures - Ocular health - Nursing intervention.

${ }^{1}$ Monografia Especialização em Enfermagem Médico - Cirúrgica / UECE, Auto-Ajuda em Saúde Ocular/CNPq.

${ }^{2}$ Especialista em Enfermagem Médico-Cirúrgica. Bolsista de Aperfeiçoamento em Pesquisa/ CNPq.

${ }^{3}$ Prof ${ }^{\mathrm{a}}$ Titular de Fundamentos de Enfermagem, DENF/UFC. Professora Pesquisadora. 
RESUMEN: La visión permite asimilar el ambiente, auxiliando en la construcción del conocimiento. El recién nacido necesita de tiempo para desarrollar algunos órganos y sentidos, dentro de ellos la visión. La estimulación visual precoz en el prematuro puede prevenir atrasos en su desarrollo psico-motor y social, permitiendo evaluar la función visual. En este estudio un grupo experimental fué sometido al proceso de estimulación y evaluación visual y outro, el control, fué apenas evaluado. El análisis de los datos consideró el tiempo de exposición, los utensilios utilizados, el número de dias y la respuesta a la estimulación. Fué constatado que los recién nacidos sometidos a la estimulación visual se mostraron alertas, activos y atentos: los del grupo control se mostraron desinteresados y poco activos frente al estímulo. Se notó que el programa de estimulación permitirá detectar disturbios visuales por la avaliación constante de las respuestas.

UNITÉRMINOS: Estimulación visual - Prematuros - Salud ocular - Intervención de Enfermería.

\section{INTRODUÇÃO}

A saúde preventiva tem tomado espaços cada vez maiores nos campos de estudo e prática profissionais. Há uma notória preocupação por parte dos profissionais de saúde em prevenir.

No campo da saúde curativa também cresce a preocupação em prevenir seqüelas, intervindo em tempo hábil a fim de atenuar ou evitar danos futuros.Com o pensamento voltado para o futuro é que a ciência desenvolve novas tecnologias e novos conceitos. Na década de 60 , houve um grande avanço cientifico, com novo impulso na década de 90 . Acompanhando este crescimento, as ciências voltadas para o estudo da pediatria sofreram grandes transformações.

As novas idéias acerca da capacidade do recém-nascido fizeram com que ele deixasse de ser visto como um ser de poucos reflexos, como "(...) uma massa sem formas, prestes a ser modelado pelo meio ambiente" (Brazelton et al., 1987:9), para ser aceito como um ser complexo que interage com o meio, modelando-o e que possui coordenação, mesmo no periodo pré-natal, completando seu desenvolvimento no periodo pós-natal até alcançar a sutileza de gestos e juizo crítico.

Brazelton et al. (1987:3) ainda afirmam que não podemos considerar o bebê

"como invisível, caótico ou imprevisível; nós o vemos como estando equipado com reações altamente previsíveis a todos os estímulos vindos do exterior (...)."

Desde a concepção até o nascimento, o recém-nascido passa por vários estágios de desenvolvimento até alcançar a sua complexidade, processo que é contínuo e sofre várias modificações. Na vida intra-uterina, o feto tem satisfeitas todas as suas necessidades e vive harmoniosamente embalado pelo som da voz 
de sua mãe, pelo movimento do seu corpo e pelo calor. Com o nascimento ocorre uma ruptura; é cessada a sensação de bem-estar, passará por situações desconfortáveis, será colocado em ambiente estranho, sofrerá manipulações bruscas e receberá estímulos exacerbados como luzes fortes, frio, barulho intenso, tudo isto em situação de impotência.

O recém-nascido em termo sofrerá todo este choque, porém poderá entrar em contato físico com a mãe, ser colocado ao seio e ter suas necessidades saciadas. O recém-nascido pré-termo necessitará de intervenção médica e de enfermagem para atender suas necessidades vitais. Será levado a uma unidade de internação onde seräo realizadas as intervenções necessárias.

Os recém-nascidos prematuros assistidos em Unidades de Terapia Intensiva Neonatais encontram-se expostos a riscos oculares, dentre eles as oftalmias neonatais e a retinopatia da prematuridade, sendo a última causadora do maior número de casos de cegueira entre bebês prematuros, segundo Rocha (1987). A retinopatia da prematuridade decorre do uso de incubadoras e oxigenioterapia, e da imaturidade pulmonar.

A OMS estimou, em 1984, que o número de pessoas cegas no mundo era de 20 milhões e que, no ano 2000 , chegariam a 40 milhões e considera que dois terços dos casos de cegueira seriam evitáveis. Percebe-se a necessidade de uma maior atenção à saúde preventiva (BOLETIM da OFICINA SANITÁRIA PAN-AMERICANA, 1984). Na Unidade de Terapia Intensiva Neonatal, a prevenção pode ser realizada através da avaliação ocular, que poderá dar indícios de patologias geradoras de distúrbios oculares.

A estimulação sensorial é utilizada atualmente para os casos confirmados de distúrbios oculares, com o intuito de auxiliar no desenvolvimento e interação do individuo ao meio em que vive. A literatura não faz referência à estimulação visual em bebês prematuros, o que dificulta que se tenha, no momento, a perspectiva de seus resultados; frente ao exposto, justificam-se os objetivos de: Elaborar um programa de estimulação visual para recém-nascidos prematuros; Aplicar o programa de estimulação visual em grupo de recém-nascidos; e Comparar a resposta do grupo submetido ao programa a outro sem estimulação.

\section{A Vida Intra-uterina e as Percepções}

Mussen, apud Moreira e Silva (1977:3), afirma ser

"bastante curioso que, embora reconheça-se ter a vida do novo indivíduo início na sua concepção, identifica-se sua idade a partir do momento do parto. Poderia quase parecer que estamos implicitamente dizendo que os eventos da vida de uma pessoa anteriores ao seu nascimento, são de pouca importância na determinação do curso futuro do seu desenvolvimento. Esta atitude é especialmente possível de ser aplicada às concepçôes de desenvolvimento psicologico. No entanto, o ambiente no qual cresce, a criança ainda em gestação pode ser de uma importância transcendental na medida em que influencia os futuros padrões de crescimento, não somente físico como também psicológico". 
Após a concepção inicia-se o periodo de desenvolvimento pré-natal do feto, que é dividido em três fases: fase pré-embrionária ou fase do ovo, fase embrionária e fase fetal. A fase pré-embrionária ou fase do ovo ocorre nas primeiras três semanas após a concepção, quando os tecidos do ovo crescem e diferenciam-se em três camadas germinativas. A partir da quarta semana até a oitava desenvolve-se a fase embrionária. Nesta fase as células diferenciam-se e organizam-se rapidamente, e surgem os primórdios da região bucal, do trato gastrointestinal e figado, também a região da cabeça e do cérebro estão diferenciadas. Neste periodo, qualquer interferência no desenvolvimento pode gerar anomalias genéticas. Quando o embrião alcança o final da oitava semana de gestação, inicia-se a fase fetal, onde ocorre a definição das formas e funções orgânicas.

No concernente ao sistema pulmonar e nervoso central, Ziegel e Cranley (1986) e Moreira e Silva (1986) colocam que da nona à décima segunda semana de gestação é definida a forma pulmonar, as pálpebras do feto fecham, os membros movem-se harmoniosamente, aparecem súbitos espasmos com extensão de todo corpo e o feto pula dentro do saco gestacional trazendo as mãos em direção à cabeça. Da décima terceira à décima sexta semana gestacional surgem movimentos respiratórios fracos, os membros inferiores realizam movimentos de extensão e o feto toca as superfícies uterinas movimentando todo corpo freqüentemente. Entre a décima sétima e a vigésima semana gestacional desaparecem os movimentos de extensão e flexão abruptos, o feto explora o próprio corpo com as mãos movimentando os dedos, pés, pálpebras e boca e procura equilibrar a cabeça deixando-a mais retificada. Entre a vigésima primeira e a vigésima quarta semana gestacional o feto já pode chorar, é iniciada a produção de surfactante pulmonar e o pulmão torna-se mais vascularizado. Da décima quinta à décima oitava semana gestacional desenvolvem-se os alvéolos pulmonares, o pulmão é capaz de realizar as trocas gasosas e a freqüência respiratória torna-se aumentada, ocorre a abertura dos olhos e o feto apresenta rotação do tronco e cabeça em direção ao estímulo mecânico. Da décima nona a trigésima segunda semana gestacional o reflexo de sucção está presente e o feto responde a estimulos auditivos e visuais. Da trigésima terceira à trigésima sexta semana gestacional inicia-se a estabilização da quantidade de surfactante pulmonar, o feto consegue coordenar sucção e deglutição e é iniciado o ciclo de sono e vigília. Entre a trigésima sétima e a quadragésima semana gestacional o pulmão possui surfactante o suficiente para permitir a função respiratória.

O desenvolvimento do bebê envolve aspectos biológicos e psicológicos que dependem da maturação do SNC, devendo acompanhar um potencial genético em relação intima com as condiçōes ambientais.

\section{O Nascimento e a Vida Preceptiva}

Após o nascimento há um rápido crescimento cerebral que perpetua até o segundo ano pós-natal. 
"O cérebro amadurece rapidamente em um processo integrado e ordenado. Cada função nova é incorporada às já existentes. À medida que prossegue o desenvolvimento, uma regulamentação cada vez maior do comportamento é desempenhada pelo córtex cerebral. Movimentos generalizados são substituídos por respostas individuais específicas. $O$ rápido desenvolvimento da consciência, da individualidade e da reatividade ao meio ambiente indica a maturidade cerebral em processamento" (Ziegel e Cranley; 1986).

Ao nascimento, a função cortical cerebral encontra-se na fase inicial de amadurecimento, permitindo a presença de reflexos que, condicionados, vão formar a base para o desenvolvimento psicomotor. Um conjunto de reflexos estão presentes ao nascimento, com a compreensão de que reflexos são respostas psicomotoras a estímulos externos, indicativos do desenvolvimento normal do sistema nervoso central, que com o passar do tempo vão sendo substituidos por respostas voluntárias.

Os reflexos que devem estar presentes ao nascimento são o reflexo de Moro, Tônico do pescoço, Rotação da cabeça, Preensão, Tração, Fuga, Posição, Baabinski e Alimentar. A presença prolongada ou a ausência destes reflexos funcionam como indicativos de anomalias no sistema nervoso central, no entanto, para que seja avaliada a presença destes, faz-se necessário atentar para o estado de consciência em que se encontra o recém-nascido. Os estados de consciência estão divididos em estados de sono e vigilia, segundo Ziegel e Cranley (1986)

O estado de sono está dividido em sono profundo e sono leve. No estado de sono profundo o bebê apresenta

"respiração regular, olhos fechados, nenhuma atividade espontânea, exceto sobressaltos ou contrações espasmódicas a intervalos relativamente regulares. Os estímulos esternos produzem sobressaltos com algum retardo, a supressão do sobressalto é rápida e as alterações de estado são menos prováveis que nos outros estados. Nenhum movimento ocular" (Ziegel e Cranley; 1986:497). No estado de sono leve "os olhos mantêm-se fechados com rápidos movimentos oculares podendo ser observados sob a pálpebra fechada, baixa atividade com movimentos fortuitos e sobressaltos, responde a estímulos internos e externos com alarme, freqüentemente acompanhado por modificação de estado. A respiração é irregular, ocorrendo movimentos esporádicos de sucção" (Ziegel e Cranley; 1986: 497).

O estado de vigilia divide-se em quatro fases: sonolento, atento ou de vigilia tranqüila, olhos abertos ou vigilia alerta, e choro. Segundo Ziegel e Cranley (1986:497), no estado sonolento "os olhos podem estar abertos ou fechados, pálpebras trêmulas, nível de atividade variável, com sobressaltos brandos de tempos em tempos, reativo a estímulos sensoriais, mas com respostas lentas e 
movimentos calmos." Quando atento o bebê possui "olhar satisfeito, parece totalizar sua atenção no ponto de estimulação como um objeto de volta a ser sugado, a atividade motora é mínima." Com olhos abertos "a atividade motora é considerável com movimento de extensão das extremidades e mesmo alguns sobressaltos espontâneos, é reativo à estimulação externa com aumento do sobressalto ou da atividade motora." No estado de choro, o bebê apresenta choro, intenso de difícil interrupção com estímulos.

Juntamente com o estado de consciência podem ser observados estados comportamentais em que o recém-nascido, quando estimulado repetidamente, seqüencialmente, pára de responder, o que permite supor que se acomoda diante de algo que o incomoda; vira-se em direção ao estímulo; coordena movimentos, leva a mão à boca e consola-se quando irritado.

"O comportamento que representa as reaçôes do bebê torna-se o precursor do desenvolvimento futuro" (Brazelton et al.; 1987:10). Em um equilibrio de energias internas e externas é que há o desenvolvimento do sistema nervoso, permitindo o desenvolvimento emocional e cognitivo.

\section{As Condições Gestacionais, o Recém-nascido e as Percepçōes}

Toda avaliação e condição do bebê ao nascimento perpassa pela situação gestacional que pode ser de risco ou em risco. De acordo com Ziegel e Cranley (1986), as gestações de risco incluem complicações peculiares, tais como vômitos perniciosos, placenta prévia, deslocamento prematuro de placenta, trabalho de parto prematuro, gestação prolongada, doenças isoimunes, doenças hipertensivas da gestação, polidrâmnio e morte fetal. As gestações em risco incluem infecções na gravidez, insuficiência renal crônica, doença da tireóide, doença cardiovascular, diabetes mielites e idade avançada da gestante.

As complicações gestacionais influem no tempo de nascimento do bebê, bem como no retardamento do crescimento mental. Devido a estas complicações, o bebê pode nascer antes do tempo, recebendo a classificação de prematuro (com menos de 37 semanas de gestação), a termo (entre 37 e 42 semanas gestacionais) ou pós-termo (após 42 semanas gestacionais).

Um bebê prematuro necessita de cuidados especiais, posto que sua condição fisiológica não permite que se exponha a riscos ambientais, necessitando, assim, de ser levado a uma unidade hospitalar também especial, a unidade de terapia intensiva neonatal. Ali, receberá os cuidados imediatos e necessários para mantê-lo em condiçōes satisfatórias de funcionamento. Será colocado em incubadora e seu manuseio ocorrerá a cada duas ou três horas sem que seja retirado da mesma.

" $A$ incubadora separa o bebê dos estímulos sensoriais que existem no meio ambiente do neonato normal e se o bebê apenas tem as fraldas trocadas e é alimentado, a quantidade de estímulos que receberá será insuficiente" (Ziegel e Cranley; 1986: 591). Ao permanecer em uma incubadora e em oxigenoterapia, o 
bebê encontra-se exposto não apenas à privação de estimulos sensoriais mas também a riscos oculares, dentre eles o principal é a retinopatia da prematuridade, que leva, na maioria dos casos, à cegueira.

A retinopatia da prematuridade, segundo Miura e Prociany (1997:531), pode ser definida "como um processo fibroso patologico que envolve bilateralmente a retina do prematuro." As causas que desencadeiam esta patologia estão relacionadas ao uso de oxigênio, cujo excesso na incubadora causa vasoconstrição retiniana, pois, ao sair da incubadora, com a queda da concentração de oxigênio, a retina sofre uma hipóxia que estimula uma neovascularização; também a hiperóxia gerada pela diferença da concentração de oxigênio entre o espaço intra-uterino e o ar ambiente pode ser apontada como causa desta patologia.

A freqüência da retinopatia encontra-se inversamente proporcional ao peso de nascimento e à idade gestacional do recém-nascido. A ação preventiva da retinopatia envolve o uso limitado de oxigênio, a identificação do grupo de risco, a exposição mínima ao ar ambiente quando em uso de oxigênio, através do manuseio mínimo e a avaliação ocular. O desmame do oxigênio, que é a redução progressiva do gás até chegar aos niveis fisiológicos para que não haja uma queda brusca de concentração e tragas danos ao recém-nascido, encontrase nesta lista.

Os bebês prematuros extremos ou muito enfermos necessitam de proteção excessiva, devendo receber o mínimo de manuseio possivel, reservando suas energias para que se mantenham vivos. No entanto, tão logo passe este período e apresentem melhora do quadro clínico, eles deverão ser estimulados sensorialmente para que desenvolvam sua percepção cognitiva e motora, que, conforme Day (1972), é contato que o organismo mantém com seu ambiente, seu estado interno, sua própria postura e movimento.

O desenvolvimento da percepção está relacionado à maturidade do Sistema Nervoso Central e desenvoltura dos sentidos e é através destes que se faz o contato com o meio para que haja uma apreensão e aprendizado do mesmo. Dentre os sentidos, a visão é a responsável pela assimilação de um maior número de informações, subsidiando o refinamento dos demais sentidos, seu desenvolvimento inicia por volta da vigésima nona semana gestacional, quando o feto pisca os olhos na presença da luz e perpetua até o sexto ano de vida quando a criança consegue distinguir cores, contrastes, perceber reflexos, ver à distância e reconhecer figuras familiares.

O recém-nascido é capaz de focalizar um objeto a uma distância de 20 a 30 $\mathrm{cm}$ do campo visual, ouve e direciona a cabeça para o som, percebe o cheiro do leite materno, direcionando a face e é sensivel ao toque, principalmente nas extremidades dos membros e região oral. Ele necessita de movimento, proteção, carinho, alimentação e higiene para crescer e também necessita ser aceito, bem recebido para organizar-se e adaptar-se, ao meio. Para adaptar-se, o bebê precisa assimilar o meio através de ações como olhar, sentir, ouvir, tocar e 
necessita acomodar-se, modificando as ações; assim desenvolve o conhecimento pela interação e ação sobre o meio.

Compreendendo, então, que o recém-nascido traz uma bagagem genética, que existem condições determinadas pela história gestacional e que os estímulos oferecidos pelo ambiente são responsáveis pelo desenvolvimento da vida perceptiva, procuramos estudar a resposta visual de recém-nascidos prematuros.

\section{Programa de Estimulação Visual para Recém-nascidos Prematuros}

São conhecidos os programas de estimulação visual chamados precoces, indicados para crianças com diagnóstico médico de comprometimento da função visual. Estes programas têm duas finalidades básicas, a saber, estimular a função visual residual e desenvolver os outros órgãos perceptiveis de maneira a integrar a criança ao ambiente.

Os recém-nascidos ditos de risco, entre os quais se incluem os prematuros, devem ser avaliados por oftalmologista na busca de comprometimentos visuais. Nem todos chegam a ser examinados e, quando o são, geralmente restringe-se a uma consulta. O que propomos, aqui, é um Programa de Estimulação Visual destinado ao recém-nascido prematuro, que respeita os princípios da estimulação visual e os adequam à capacidade de resposta do prematuro.

A estimulação visual em uso atualmente é indicada para ser iniciada quando a criança completa aproximadamente três meses e as sessões têm duração de 15 a 50 minutos, de acordo com a tolerância demonstrada pela criança. Lembrando que o recém-nascido prematuro encontra-se com suas estruturas fisiológicas imaturas, internado em uma unidade especializada, via de regra na incubadora, privado de estímulos sensoriais e afetivos naturais. Assim, considera-se pertinente submetê-lo à estimulação visual. Segue a descrição do método.

Recomenda-se a utilização de três artefatos, a saber: um retângulo de aproximadamente $15 \mathrm{~cm}$ de largura por $10 \mathrm{~cm}$ de altura, com listras verticais com $1,5 \mathrm{~cm}$ de largura, nas cores preto e branco intercaladas. $O$ segundo artefato constitui-se de um círculo de aproximadamente $10 \mathrm{~cm}$ de diâmetro, com um desenho concêntrico alternando a cor cinza e branca. O terceiro objeto é um mobile com três bolas pequenas de isopor nas cores azul, vermelha e amarela.

Justifica-se a utilização de diferentes cores e formatos para que haja modificação da estimulação visual. Deve-se buscar o equilibrio entre cores e formas para que o recém-nascido forme a memória visual mas não ocorra a monotonia na estimulação. Portanto, os artefatos serão utilizados sequencialmente, repetindo-se a cada três dias.

Conforme sabemos, o campo visual do recém-nascido está localizado a $30 \mathrm{~cm}$ dos seus olhos, portanto esta será a distância de exposição dos artefatos à sua frente. Deve-se observar atentamente as suas reações para se certificar que seu olhar foi captado pelo objeto ou, se preferir, que seu olhar captou o objeto. 
Para a realização da sessão de estimulação visual, deve-se observar que o recém-nascido encontre-se em estado de vigílía alerta espontânea, ou seja, não será acordado para ser estimulado, mas sim, utilizarmos um momento espontâneo de vigília. O ambiente deverá estar calmo, suficientemente iluminado, temperatura próxima a $36^{\circ} \mathrm{C}$, o recém-nascido confortável, ou seja, higienizado e alimentado.

O tempo médio considerado ideal para a exposição é de quatro minutos, podendo oscilar entre três a cinco minutos obedecendo a tolerância do recémnascido. Caso apresente sinais de irritabilidade, sono ou choro, a estimulação deverá ser suspensa; mas, demonstrando vivacidade e interesse, o tempo poderá ser estendido. Recomenda-se não exceder os cinco minutos.

As respostas observadas no recém-nascido podem ser caracterizadas em Não Reagente, quando olha para o objeto mas não demonstra interesse; Pouco Reagente, quando olha para o objeto, porém não fixa o olhar por muito tempo; Reagente, quando olha para o objeto, fixa o olhar, mas não acompanha quando movimentado; e Intensamente Reagente, quando olha para o objeto, fixa o olhar e acompanha seus movimentos.

Sintetizando, a estimulação visual será empregada com o prematuro confortável, em vigilia alerta espontânea; será utilizado um artefato por dia com revezamento entre eles; a exposição será observada; as respostas serão classificadas em Não Reagente, Pouco Reagente, Reagente e Intensamente Reagente e serão registradas no prontuário; será perseguido o objetivo de captar o olhar e evoluir do ponto fixo para o movimento.

\section{METODOLOGIA}

A população constituiu-se de recém-nascidos prematuros internados em Unidades de Terapia Intensiva Neonatais. Os critérios para seleção da amostra foram ter no mínimo vinte e nove semanas de vida gestacional, pesar no minimo $1.100 \mathrm{~g}$, não possuir patologias que comprometam o desenvolvimento do sistema nervoso central, ter superado o estado patológico crítico.

O minimo de vinte e nove semanas gestacionais justifica-se pelo fato de que com esta idade o feto apresenta os primeiros sinais de percepção visual. O peso mínimo de $1.100 \mathrm{~g}$ se dá devido ser esta a média de peso encontrada em fetos com a idade gestacional de vinte e nove semanas. O peso comparado à idade gestacional permite o reconhecimento do desenvolvimento fetal adequado. A ausência de patologias no sistema nervoso central leva a crer que o sistema perceptivo está íntegro.

Para a seleção da amostra, foram examinados os prontuários, buscando-se aqueles recém-nascidos que preenchiam os quesitos estabelecidos. Os dados de identificação do binômio mãe-filho foram registrados em impresso próprio.

Por se tratar de pesquisa experimental, a amostra foi subdividida em Grupo Controle e Grupo Experimental. O Grupo Experimental foi submetido ao Programa de Estimulação Visual já descrito anteriormente. O Grupo Controle foi exposto uma vez ao estímulo visual, em data próxima à alta provável, correspondendo ao mesmo período de internação e alta do Grupo Experimental.

Os dados são apresentados em gráficos de barras, com duas variáveis, primeiramente analisando o Grupo Experimental quanto à resposta visual frente 
à exposição do estimulo parado e móvel, ao tempo de exposição, à variação da resposta. A segunda análise é comparativa entre os dois grupos, Controle e Experimental, buscando-se saber se foram não reagentes, pouco reagentes, reagentes ou intensamente reagentes ao estímulo.

\section{RESULTADOS}

Seis mães eram do grupo experimental, sendo que uma delas teve parto gemelar, e encontravam-se na faixa etária de 20 a 30 anos. Quanto à história materna, nenhuma teve caso de aborto, quatro eram primiparas e duas multiparas.

$\mathrm{Na}$ gestação atual, duas mães apresentavam doença hipertensiva da gestação e quatro iniciaram trabalho de parto prematuro; segundo Ziegel e Cranley (1986), dentro das complicações obstétricas, fazem parte do grupo de gravidez de risco, onde complicações próprias da gestação podem levar a um alto indice de mortalidade e mobidade, incluindo a prematuridade fetal.

Sete mães, cujos bebês participaram do grupo controle, estavam na faixa etária de 20 a 30 anos, e tiveram como história materna um caso de aborto, três primiparas e quatro multíparas. No tocante à gestação atual, foram três casos de doença hipertensiva da gestação e quatro de trabalho de parto prematuro. Ambos os grupos de mães mantiveram uma certa homogeneidade quanto às suas caracteristicas.

Os recém-nascidos prematuros que participaram do grupo experimental totalizaram sete bebês, cujas idades gestacionais compreenderam de trinta a trinta e quatro semanas, com peso adequado para a idade gestacional, posto que o peso de acordo com a idade gestacional fornecem indicios do desenvolvimento orgânico do bebê, permitindo afirmar que estes bebês encontram-se com características neurofisiológicas adequadas dentro do periodo fetal.

Como diagnóstico clínico dos bebês deste grupo, predominou a síndrome do desconforto respiratório com cinco casos, houve ainda um caso de membrana hialina e um de anóxia pós-parto. São patologias que acometem o sistema respiratório, não descartando suas implicações no sistema orgânico do bebê como um todo. Houve, então, a necessidade do uso de incubadora e oxigenioterapia dentre outros artificios, o que os potencializam como bebês de risco para distúrbios oculares e, também, como afirma Herren e Herren (1986), dificuldades psicomotoras.

Participaram do grupo controle também sete recém-nascido, com idade gestacional de vinte e nove a trinta e quatro semanas gestacionais, possuindo peso de nascimento adequado para a idade gestacional. Quanto ao diagnóstico clínico, foram quatro os casos de síndrome do desconforto respiratório, dois de membrana hialina e um de anóxia pós-parto. Precisaram, então, de assistência especializada, fazendo uso de oxigênio e incubadoras, o que os coloca entre os propensos a riscos oculares.

Também os recém-nascidos do grupo controle e experimental guardaram uma homogeneidade quanto às suas características. Polit e Hungler (1995) colocam que, para uma pesquisa ser considerada experimental, ela deve possuir três propriedades: manipulação, controle e distribuição aleatória. $\mathrm{Na}$ 
manipulação, o investigador deve experimentar algo. Para experimentar algo deve haver condições para controlar o experimento através de um grupo designado como controle. A distribuição para o grupo que será experimentado e o grupo que será o de controle deverá ocorrer de forma aleatória.

O grupo controle não passou pelo programa de estimulação visual, ele foi exposto ao estímulo visual e avaliado quanto à sua resposta.

O Programa de Estimulação Visual foi executado por enfermeira por ser, dentro de uma Unidade de Terapia Intensiva Neonatal, o profissional que ocupa posição singular para criar estímulos capazes de captar o interesse dos recémnascidos. Ela passa grande parte do tempo observando e mantendo contato com os recém-nascidos, além de possuir informações e conhecimentos necessários para saber como equilibrar momentos de atividade e repouso de forma a auxiliar no seu desenvolvimento psicomotor.

Dentre os animais, o homem possui a capacidade de ver simultaneamente com os dois olhos, ou seja, as imagens são formadas simultaneamente nas duas retinas pela focalização do objeto. Ao olhar para um objeto, o cérebro fornece a formação de uma imagem central e também de tudo que existe na área circunvizinha num ângulo de cento e oitenta graus. O que existe na área próxima ao ponto de fixação é chamado de campo visual. Como o recém-nascido capta as imagens numa distância máxima de trinta centímetros do olho, seu campo visual é reduzido. Quando colocamos cores e figuras na frente do recémnascido, dependendo do tamanho do objeto ele tomará grande parte do seu campo visual. Primeiramente ele deverá fixar o olhar em um ponto para, posteriormente, visualizar todo o restante.

A apresentação dos dados será feita em seguida, descrevendo-se os achados referentes ao Programa de Estimulação Visual, portanto, envolvendo apenas o grupo experimental.

\section{GRÁFICO 1 - RECÉM-NASCIDOS PREMATUROS EXPOSTOS A ESTÍMULO VISUAL E EVOLUÇÃO DA RESPOSTA A OBJETO FIXO E MÓVEL}

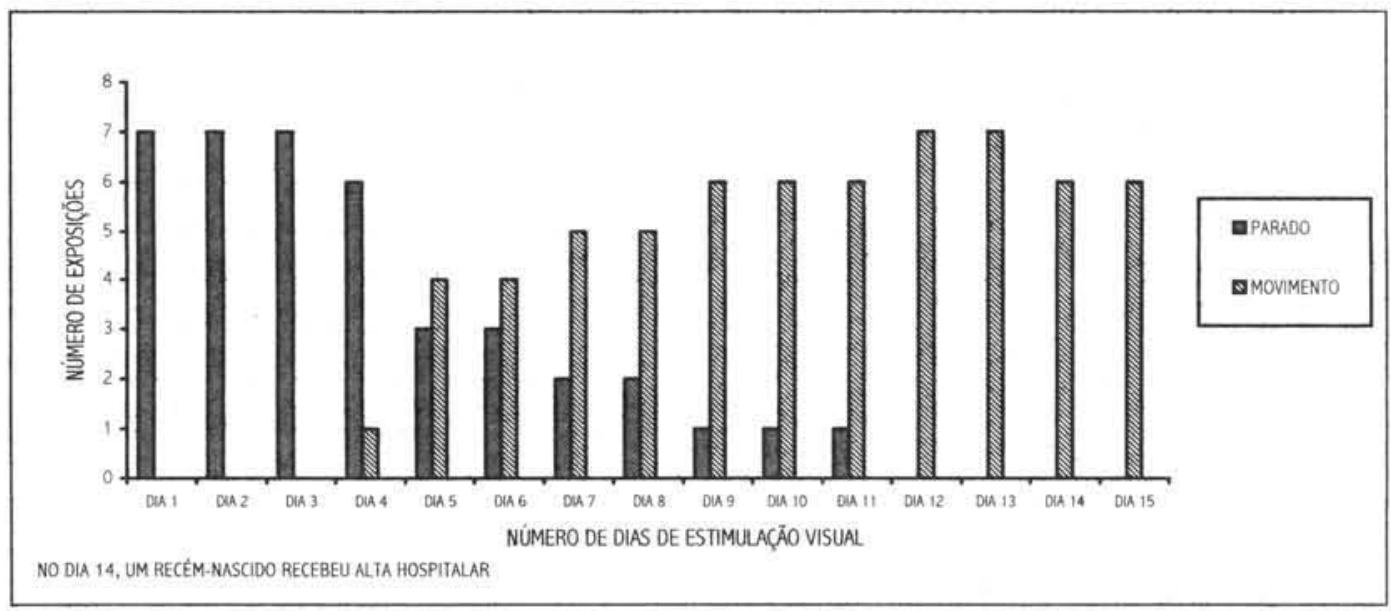

R. Bras. Enferm. Brasilia, v. 51, n. 2, p. 189-206, abr./jun., 1998 
Este gráfico apresenta os sete recém-nascidos expostos à estimulação visual, pelo periodo de 15 dias consecutivos e a sua reação, estando o objeto de estimulação parado ou em movimento. Ao todo foram realizadas cento e três sessões de estimulação, isto porque um recém-nascido teve alta da unidade no $14^{\circ} \mathrm{dia}$.

Nos três primeiros dias, o objeto para a estimulação foi colocado no campo visual do recém-nascido na tentativa de que o mesmo o percebesse e indicasse interesse, fazendo com que ele mantivesse contato visual com o objeto.

No quarto dia de estimulação, foi iniciada a primeira exposição com o objeto em movimento. Foi percebido que um dos recém-nascidos conseguiu olhar para o objeto e fixá-lo por algum tempo; tentou-se movimentar lentamente o objeto para os lados, sempre respeitando seu campo visual, a fim de que acompanhasse o objeto. Os resultados satisfatórios indicaram que os bebês já estavam preparados para a nova etapa.

No quinto e sexto dias, três recém-nascidos reagiram à exposição do objeto para estímulo visual, estando este fixo, mas foram incapazes de acompanhá-los em movimento. Os quatro restantes, após fixarem o olhar no objeto, foram capazes de seguir os lentos movimentos realizados à direita e esquerda.

No sétimo e oitavo dias de trabalho, dois recém-nascidos reagiram à exposição com o objeto parado e cinco com o objeto em movimento.

Do nono ao décimo primeiro dias seis recém-nascidos reagiram à estimulação visual com o objeto parado e em movimento e apenas um respondeu com o objeto parado, ou seja, quando se movimentava o objeto, seu olhar não se fixava. Do décimo segundo ao décimo quinto dias, os objetos usados como estímulo foram movimentados no campo visual.

Constatou-se que o recém-nascido precisa ser estimulado repetidas vezes para apresentar respostas positivas, ou seja, a repetição do estimulo auxilia no aprendizado através da assimilação do meio. A freqüência da estimulação visual foi de quinze dias ininterruptos.

Em relação ao número diário de exposições, esta foi realizada apenas uma vez ao dia, devido à característica do sono do recém-nascido e ser necessário que ele esteja em vigilia alerta. Segundo Brazelton et al. (1987), este é o melhor estado para estimular o bebê, pois ele encontra-se mais atento aos objetos e sons que o rodeiam, é mais fácil captar sua atenção, ele se mantém calmo e pacifico. 


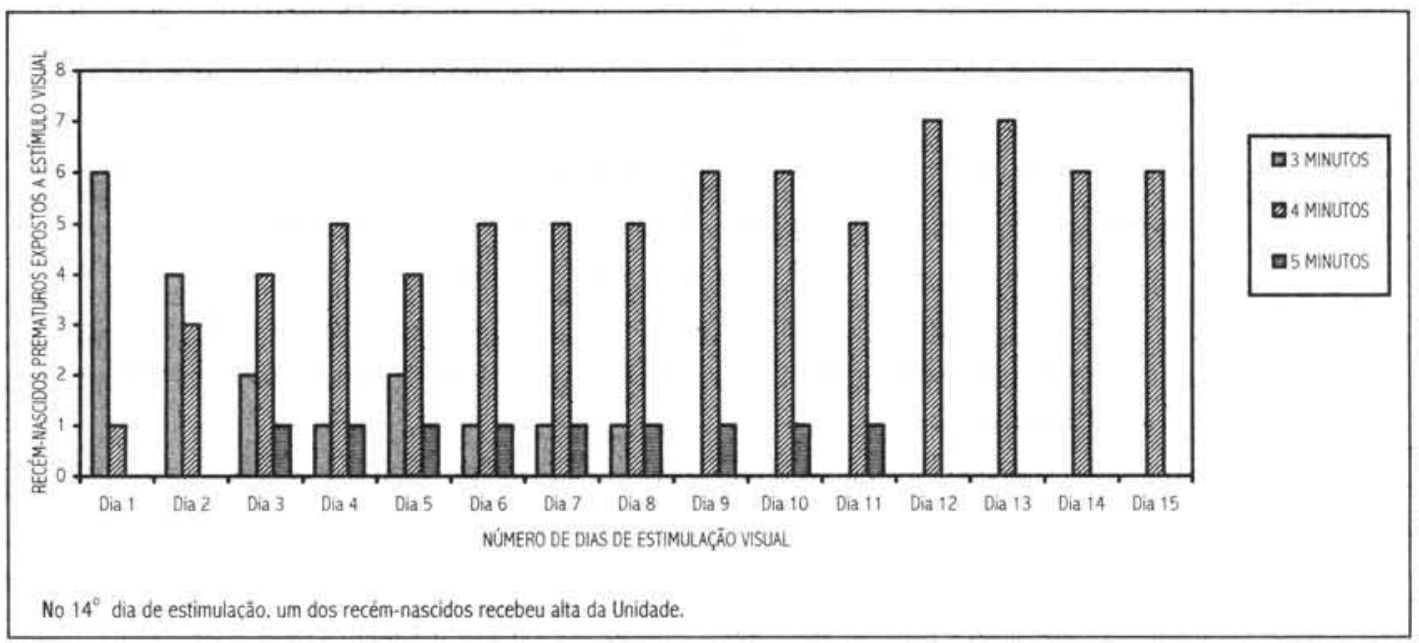

Foram realizadas diariamente sete estimulaçöes, respectivamente, uma com cada recém-nascido da amostra, que iniciaram com os tempos de três e quatro minutos. No primeiro dia, seis responderam à exposição com os tempos de três minutos e um com quatro minutos. Optou-se por iniciar com três minutos devido à atenção do pré-maturo não ser muito prolongada.

No segundo dia, quatro recém-nascidos reagiram à estimulação por três minutos. No terceiro dia dois bebês reagiram com três minutos, quatro com quatro minutos e um com cinco minutos. Foi aumentado o tempo de exposição com um dos bebês para cinco minutos porque ele não demonstrou sinal de cansaço.

No quarto dia de estimulação, um recém-nascido reagiu à exposição por três minutos, cinco por quatro minutos e um por cinco minutos. Um dos tempos de exposição do estímulo mudou de três para quatro minutos porque o bebê aceitou um tempo maior e respondeu à estimulação.

No quinto dia, tornou-se a ter dois bebês com exposição de três minutos ao estímulo, quatro bebês de quatro minutos e um de cinco minutos. Uma das exposiçōes retornou a três minutos devido ao fato de o bebê não ter alterado sua resposta. Os demais mantiveram-se inalterados por estarem respondendo satisfatoriamente aos tempos de quatro e cinco minutos de exposição.

No sexto, sétimo e oitavo dias de estimulação, um recém-nascido reagiu à exposição com um tempo de três minutos, cinco responderam com quatro minutos e um com cinco minutos. Alterou-se novamente o tempo de exposição para um bebê na tentativa de melhorar sua resposta.

No nono e décimo dias, seis bebês responderam ao estímulo com quatro minutos de exposição e um com cinco minutos. A mudança nos tempos de exposição se deu por terem tolerado bem os tempos de quatro e cinco minutos e 
por três minutos ter se mostrado insuficiente, ou seja, os bebês expostos ao estimulo com três minutos de duração suportaram a exposição com quatro minutos sem demonstrarem cansaço, irritação ou sono. Para um dos bebês, no décimo primeiro dia, foi aumentando o tempo de exposição para cinco minutos. Cinco recém-nascidos responderam à estimulação com quatro minutos de estimulação e dois bebês com cinco minutos. Como não houve alteração considerável nas respostas dadas pelos bebês nos quatro últimos dias de estimulação, todas as exposiçōes foram realizadas com quatro minutos.

Percebeu-se que o tempo de quatro minutos foi o tempo adequado para realizar a estimulação visual sem que o bebê emitisse sinais de cansaço, dispersão, sono ou irritabilidade. Esta resposta foi estabilizada em torno do décimo dia do programa.

No concernente às respostas dadas pelos bebês frente ao estimulo visual do grupo experimental, elas variaram em não reagentes, pouco reagentes, reagentes e intensamente reagentes. Estes dados são apresentados no gráfico 3 , a seguir.

\section{GRÁFICO 3 - VARIAÇÃO DAS RESPOSTAS DADAS PELOS RECÉM-NASCIDOS FRENTE À ESTIMULAÇĀO VISUAL}

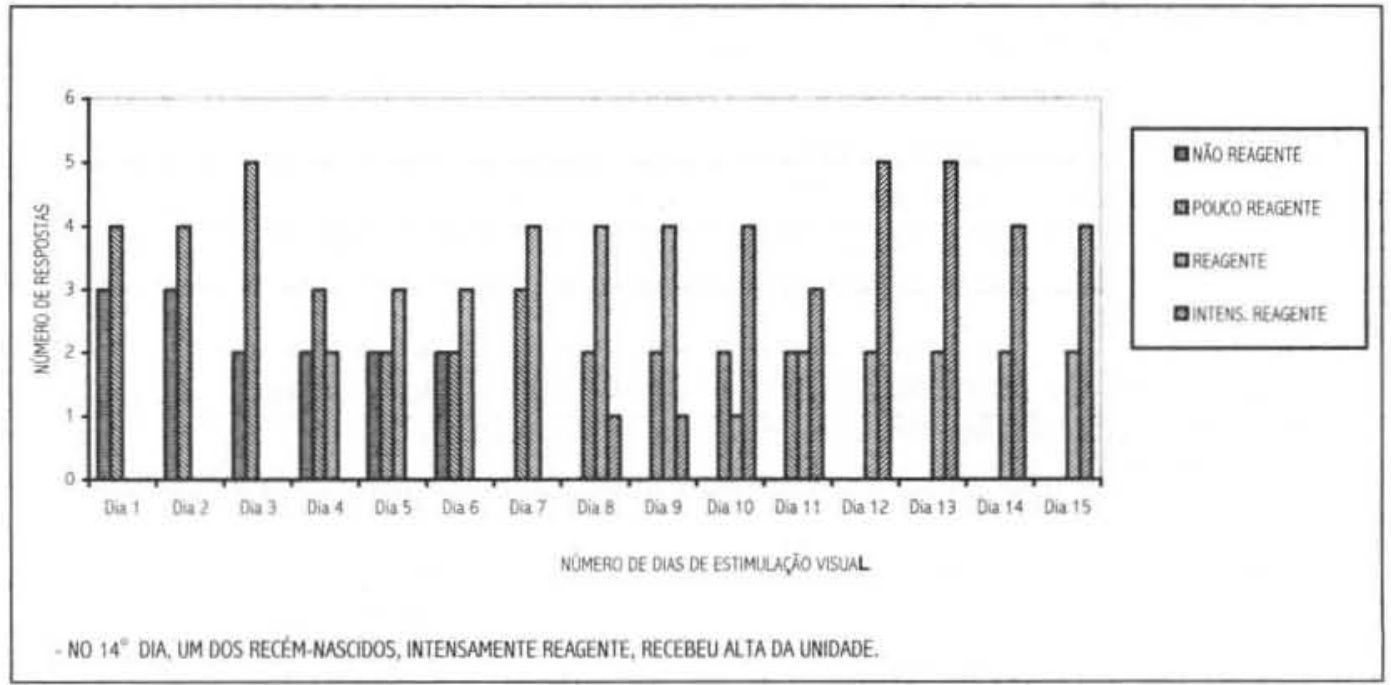

Segundo Brazelton et al. (1987), quando se consegue captar a atenção do bebê a um estimulo visual, ele reage fixando o olhar, mostrando-se ativo através de movimentos de extensão e flexão dos membros, depois apresenta-se calmo, pacifico e acompanha o objeto quando movimentado em um ângulo de cento $e$ oitenta graus. Um bebê a termo apresenta estes reflexos ao nascimento, porém um bebế prematuro poderá apresentá-los, embora com lenta evolução.

Na vigésima nona semana gestacional, o bebê apresenta reflexo à luz e, por volta da trigésima sexta semana gestacional, é capaz de visualizar o rosto materno, cores fortes e contrastes, quando em seu campo visual de vinte a trinta centímetros. 
No primeiro e segundo dias de estimulação visual, três recém-nascidos foram não reagentes e quatro foram pouco reagentes, significando afirmar que três não olharam para o objeto e não demonstraram interesse, e quatro olharam para o objeto, porém não fixaram o olhar por muito tempo. No terceiro dia de estimulação visual, houve duas respostas não reagentes e quatro pouco reagentes.

No quarto dia, ocorreram duas respostas não reagentes, três reagentes e duas pouco reagentes. Os dois bebês que reagiram à estimulação conseguiram olhar para o objeto e fixar o olhar, porém não o acompanharam quando colocado em movimento. Três olharam para o objeto e fixaram o olhar por algum tempo e dois não demonstraram interesse pelo estímulo.

No quinto e sexto dias, houve duas respostas não reagentes, duas pouco reagentes e três reagentes. Os bebês pouco a pouco vão demonstrando interesse pelo estímulo, conseguem percebê-lo em seu campo visual com mais rapidez em comparação aos primeiros dias, e mostraram-se alertas ao perceber o estimulo visual.

No sétimo dia houve três respostas pouco reagentes e quatro reagentes. Os recém-nascidos começam, a partir de então, a perceber e manter contato com o estímulo visual. No oitavo e nono dias teve-se duas respostas pouco reagentes, quatro reagentes e uma intensamente reagente. Um dos bebês acompanhou o objeto quando movimentado para os lados. Diariamente tentou-se movimentar o estimulo visual e observar as respostas que os bebês dariam. Quando não acompanhavam o movimento, o objeto era recolocado fixo no campo visual do bebê, a fim de que este conseguisse percebê-lo.

No décimo dia, houve duas respostas pouco reagentes, uma reagente e quatro intensamente reagentes. No décimo primeiro dia foram duas respostas pouco reagentes, duas reagentes e três intensamente reagentes. Houve regressão na resposta de um dos recém-nascidos.

Do décimo segundo dia ao décimo quinto, apenas duas respostas foram reagentes, o restante foi intensamente reagente, valendo ressaltar que um dos recém-nascidos teve alta no décimo quarto dia de estimulação. A alta deste não interferiu na estimulaçăo visual, posto que já acompanhava o estimulo e se mostrava bastante alerta. Dois dos bebês estimulados não chegaram a acompanhar o movimento do estímulo, porem conseguiram percebê-lo.

Pode-se pensar que alguns recém-nascidos necessitam de um prazo maior de estimulação e alerta, também, para a existência de problemas visuais.

O tempo para a realização diária da estimulação com cada bebê variou de três a cinco minutos numa tentativa de encontrar o tempo que se adequasse a cada um deles. Foi preciso conhecer o tempo necessário para estimular cada bebê, a fim de que não gerasse uma situação de cansaço, de irritabilidade e desinteresse pelo excesso de estímulo.

O excesso de estimulação sensorial gera uma desorganização neuropsíquica. Segundo Brazelton et al. (1987), o excesso de estimulo 
sensorial pode levar a um estado de irritação expressado por choro forte ou a um estado de inatividade como se o bebê dormisse. Estes artifícios são utilizados pelo bebê na tentativa de que alguém perceba sua perturbação e cesse a exposição ao estímulo, assim ele tenta controlar a estimulação proveniente do meio.

Concluida a análise do grupo experimental, passou-se à etapa comparativa entre este e o grupo controle.

No tocante ao grupo controle, este foi avaliado quanto às suas respostas frente ao estímulo visual. Os bebês prematuros pertencentes a este grupo não foram estimulados, colocou-se o estímulo visual, o cartão retangular com listras paralelas, na frente do recém-nascido, no campo visual do mesmo, para que o bebê o percebesse, fixasse o olhar e, assim observadas suas respostas. Para tanto, foi aguardado o momento em que o bebê estaria em estado de vigilia alerta; assim desperto, o bebê reage quando exposto a um estímulo sensorial.

O tempo utilizado para a exposição foi de quatro minutos, posto que com o grupo experimental se mostrou adequado, sem que fosse percebido sinais de cansaço, irritação ou sono nos bebês.

No tempo de quatro minutos, o estímulo foi colocado frente ao recém-nascido uma única vez e observada sua resposta. $O$ estímulo foi colocado parado no campo visual do bebê, evoluindo para a movimentação lenta do objeto para os lados direito e esquerdo na tentativa de captar-Ihe a atenção.

\section{GRÁFICO 4 - COMPARAÇÃO ENTRE OS GRUPOS CONTROLE E EXPERIMENTAL PARA AS RESPOSTAS AO ESTÍMULO VISUAL}

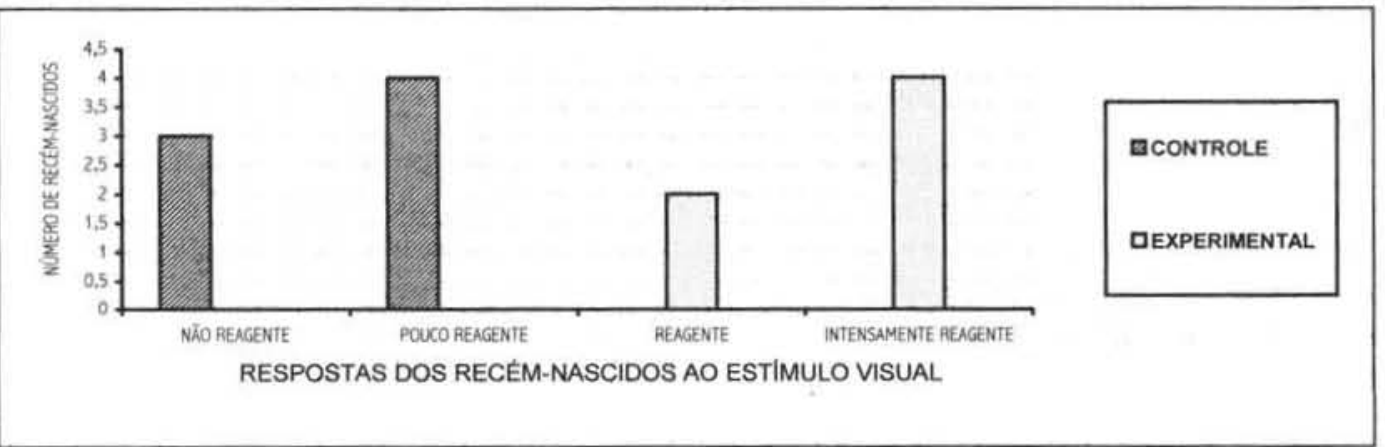

Três dos recém-nascidos prematuros pertencentes ao grupo controle responderam não reativamente à presença do estímulo, ou seja, não olharam para o objeto e não demonstraram interesse. Os outros quatro recém-nascidos responderam pouco reativamente, olharam para o objeto, porém não fixaram o olhar por um periodo mais prolongado. O estimulo foi percebido pelo bebê, mas logo dispersou o olhar. $\mathrm{Na}$ tentativa de movimentar o objeto, nenhum deles acompanhou com o olhar ou com o movimento da cabeça. 
O Gráfico 4 mostra a comparação feita entre as respostas dadas pelo grupo controle e as respostas dadas no último dia de estimulação visual do grupo experimental frente ao estímulo visual.

A diferença entre as respostas dos recém-nascidos dos dois grupos é extrema. No grupo controle, três não reagiram e quatro foram pouco reativos, significando afirmar que não demonstraram interesse, não olharam, nem fixaram o olhar. Do grupo experimental, dois dos recém-nascidos responderam olhando e fixando o olhar no estimulo, e quatro responderam olhando, fixando e acompanhando-o quando movimentado lentamente para os lados.

$\mathrm{O}$ individuo nasce programado para ver, e essa habilidade se desenvolverá através de estimulos visuais captados e armazenados no córtex visual.

A estimulação visual auxilia no desenvolvimento sensorial da criança; quando portadora de deficiências oculares ou nos casos de privação de estimulos sensoriais também funciona como método avaliativo, posto que, ao ser estimulada, será observada sua resposta; caso seja negativa, funcionará como um alerta para a existência de problemas mais graves.

Os bebês internados em Unidades de Terapia Intensiva Neonatais passam ora por privação de estimulos sensoriais ora por estimulos em excesso e desorganizados. A estimulação, sendo realizada de forma sistemática, permite ao recém-nascido o acúmulo de experiências que o auxiliam a adaptar-se mais facilmente ao meio ambiente.

\section{CONCLUSÃO}

Os achados mostram que os recém-nascidos do grupo experimental responderam progressivamente ao programa de estimulação visual, mostraramse atentos, alertas e ativos após o programa; que o tempo de quatro minutos foi suficiente para obter respostas satisfatórias, e os utensilios utilizados chamaram a atenção dos bebês, vindo reforçar a afirmativa de Brazelton et al. (1987) quanto à preferência dos bebês por cores contrastantes e fortes. Os recémnascidos do grupo controle, quando colocados frente ao estimulo, não demonstraram interesse por este, permanecendo dispersos.

Diante dos achados, pressupõe-se que a estimulação visual iniciada em uma unidade de terapia intensiva neonatal auxilia na aquisição de experiências visuais, bem como na detecção precoce de distúrbios oculares.

Considera-se o profissional habilitado para desenvolver um programa de estimulação visual, por possuir conhecimentos e informaçōes necessárias para saber como e quando intervir, e por manter durante um maior periodo de tempo contato direto com os recém-nascidos. 


\section{REFERÊNCIAS BIBLIOGRÁFICAS}

1. BRAZELTON, T. Berry; CRAMER, Bertrand; KREISLER, Léon; at all. A dinâmica do bebê. Porto Alegre: Artes Médicas, 1987.

2. BRUNO, Marilda Morais Garcia. O desenvolvimento integral do portador de deficiência visual: da intervençäo precoce a integração escolar. Săo Paulo-SP: NEWSWORK, 1993.

3. DAY, R. H. Percepção humana; trad. Maria Tereza Pereira Maldonado. Rio de Janeiro: Livros Técnicos e Científicos. 1972.

4. FUNDAÇÃO HILTON ROCHA. Ensaios sobre a problemática da cegueira. Belo Horizonte, 1987.

5. HERREN, H.; HERREM, M. P. Estimulação Psicomotora Precoce. 2. ed. Porto Alegre: Artes Médicas, 1986.

6. JOSÉ, Newton Kara; ALMEIDA, Geraldo Vicente; ARIETA, Carlos Eduardo Leite; at all. Causas da deficiência visual em crianças. Boletim da Oficina Sanitária Panamericana. Oficina Regional da Organização Mundial de Saúde, v. 97, n. 5, p. 405-413, novembro, 1984.

7. KLAUS, Marshall H.; FANAROFF, Avroy A. Alto risco em neonatologia. 4. ed.. Rio de Janeiro - RJ: Editora Guanabara Koogan, 1995.

8. MARTORELL, Patrício Fernanes; ZUÑIG, Alberto Valdez; SALAZAR, Gildardo Valência; at al. Retinopatia del prematuro-conceptos actuales. Act Pediátrica de México, México, v. 10, n. 4, p. 137-144, act/dic. 1989.

9. MIURA, Ernani; PROCIANY, Renato S. \& col. Neonatologia princípios $e$ prática. 2. ed. Porto Alegre: Artes Médicas, 1997.

10. MOREIRA, Liana Maria Almeida de Oliveira de Lavor; SILVA, Marcélia Oliveira. Primórdios da atividade psicomotora do recém-nascido. Fortaleza, 1996. Monografia (Curso de Pós Graduação em Psicomotricidade) - Centro de Ciências da Saúde, Universidade de Fortaleza.

11. PAGLIUCA, Lorita Marlena Freitag. Assistência de enfermagem ao deficiente visual. Fortaleza-CE: Imprensa Universitária U.F.C., 1993.

12. POLIT, Denise F.; HUNGLER, Bernadette P. Fundamentos de pesquisa em enfermagem. 3. ed. Porto Alegre: Artes Médicas, 1995.

13. ZIEGEL, Erna E.; CRANLEY, Mecca S. Enfermagem obstétrica. 8. ed. Rio de Janeiro: Editora Guanabara, 1986. 